\title{
Experiments for WAAM Technologies
}

\author{
Laurentiu Dan Ghenghea*
}

Technical University “Gheorghe Asachi” TCM Dep., D.Mangeron Blvd. 59, B201, Iasi, Romania

\begin{abstract}
The most recent group of technologies added to Additive Manufacturing (AM) field, Wire and Arc Additive Manufacturing (WAAM) use some well known welding processes, generally gas metal arc welding (GMAW codification at American Welding Society and 135 at International Institute of Welding/Institute International de Soudure) or Tungsten Inert Gas to manufacture products used in top ranged production field like aeronautics. Remarkable results in this new method for industrial production have been achieved by research groups from Cranfield, Delft and many other universities around the world and were published in prestigious research journals. Together with our students from Welding Engineering Program and our limited resources for powerful researches an approach to these new working technologies have been done and our main objective was to show that strong researches could be done with more resources during masters or doctoral studies. In this proposed paper some experiments with shielded metal arc welding process will be presented which have been done to investigate what are the internal structure of welded products made when bead over bead have been deposed, also will be presented some hardness tests of manufactured structure and machining tests for milling process.
\end{abstract}

\section{Introduction}

The welding processes together with metallic coatings (metallisation), thermal cutting both groups could be done with mixed oxygen and gases as flames or thermal plasma, bonding processes with metallic alloys or with polymers and special welding processes like underwater or space welding are in the front view of researchers and producers. The utilisation of welding procedures could be identified from the beginning of humanity speaking about cold pressing welding or forget welding for some metals that are native on the Earth like: gold, tin, silver. The modern welding processes have been developed as we know them today at the end of the nineteenth century by scientists like: Slavianov, Bernandos, Kjilberg and many other that used the developments from physics, chemistry and other scientific fields to materialise welding and connected to welding processes, the examples could be utilisation of: lasers, thermal plasma, $\mathrm{CNC}$, robotic, induction, high frequency currents, electronic devices for electric current frequency change (invertors).

In the recent years, no more than fifty, a new way to manufacture industrial products has been given to producers by scientific research and it is additive manufacturing (AM) that is a way to construct products layer upon layer and the first encouraging result have been made

\footnotetext{
* Corresponding author: lghenghe@tcm.tuiasi.ro
} 
with polymers which have been solidified in thin layers with heating source like ultraviolet light or lasers. This production method is totally different from known methods that subtract or redistribute the excess from raw materials and it could not be utilised. A great advantage of additive manufacturing is that it could use electronic files of models which are very quick transmitted to the execution parts, this is the reason them have been called "rapid prototyping manufacturing processes". In Figure 1 some simplified drawings for manufacturing processes are presented the first line ( $a$ and $b$ ) shows subtractive (the milling process) and redistributive process (cold deep drawing process) the final line (c and d) shows joining process (welding) and additive manufacturing using layer upon layer solidification.

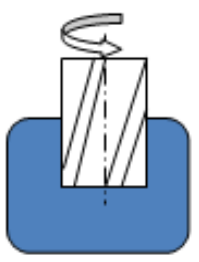

a Subtracting technology (milling process)

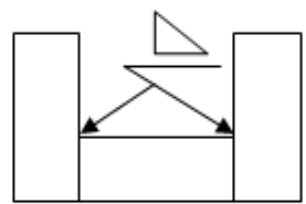

c Joining technology (corner welding)

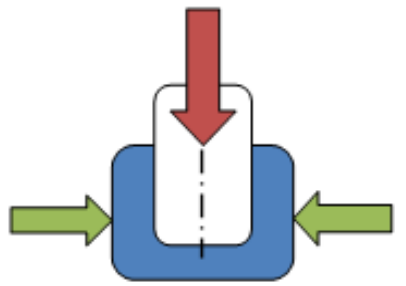

$b$ Redistributing technology (cold deep drawing)

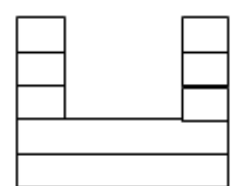

d Additive technology, layer upon layer deposition

Fig. 1. The manufacturing methods: $\boldsymbol{a}$ - cutting excess of material; $\boldsymbol{b}$ - redistribution of raw material; $\boldsymbol{c}$ - joining base materials; $\boldsymbol{d}$ - additive manufacturing.

\section{Technological processes related to additive manufacturing}

A very good survey of additive manufacturing processes it is offered by Wohler Report published each year, but in 2014 it described The History of Additive Manufacturing [1] focussed on producers of industrial installations for lot of specific technologies used in this scientific and industrial area.

In a short summary of the report it could be outlined that very different materials have been used starting with known liquid polymers (polyamides, polycarbonate, ABS) also special compositions made by producers like DuPont, powders of different types bonded with liquid binders, papers to be cut in different shapes and bond together to manufacture pieces from cross sections, metallic particle or wire and some processes use sand. Having this in view, the additive manufacturing processes could be classified in following classes counting on materials used:

1 Polymer Based Additive Manufacturing Processes;

2 Metals Based Additive Manufacturing Processes;

3 Exotic Materials Based Additive Manufacturing Processes.

The additive manufacturing equipments prices start from few hundred dollars and for complex manufacturing equipments for metal casting arrive at six hundred thousand dollars, important world manufacturers like 3 D Systems, Z Corp, Mitsubishi, EOS have been involved in equipments development and introducing its on world market. 
Important scientific initiative to develop knowledge of additive manufacturing have been done in United States of America where American Society for test and Materials founded the committee F-42 to standardize additive manufacturing terminology and to develop industry standards.

In 2009 Edison Welding Institute organised Additive Manufacturing Consortium (AMC) consisting in twenty two industrial members and partner organizations representing both large and small companies, government agencies and important universities with researches in additive manufacturing field.

The European Union have identified the additive manufacturing field as a key emergent technology fields and cooperative projects have been founded, just two examples, Custom Fit [2] and Repolac (Rapid Production of Large Aerospace Components).

The director of AMC [3] considers that for metal based additive manufacturing two main components are important: the raw material used and the energy source used to forms it and from this point of view only few technologies could be used and those are: powder bed systems where electron beam or laser are used to give the needed shape to layers from powders in enclosed environments, laser powder injection where a nozzle directed powder to laser waves and free form fabrication with electron beam melting metallic wires or arc deposition of wire and powders sometimes together with ultrasonic consolidation of metallic layers.

\section{The wire and arc additive manufacturing (WAAM)}

In the paper review about metal additive manufacturing [4,5] the author William E. Frazeir presents the group of metals used for researches and production using additive manufacturing processes and those are: Titanium (Ti-6Al-4V, ELI Ti, CP Ti, $\gamma$-TiAl), Aluminium (Al-SiMg, 6061), Tool steels (H13, Cermets), Super alloys (IN625, IN718, Stellite), Stainless steels ( 316 \& 316L, 420, 347, PH 17-4), Refractory metals (MoRe, Ta-W, CoCr, Alumina).

In the scientific meeting Titanium Europe 2015 organised by International Titanium Association at Birmingham, UK [7] researchers from Cranfield (Adrian Addison, Jialuo Ding, Filomeno Martina, Helen Lockett, Stewart Williams) and Coventry University (Xiang Zhang) presented solid results about complex Titanium parts manufacturing using wire and arc additive manufacturing considering it capability to uses available welding equipments and manipulators to produce parts of medium or high complexity at different scales.

The authors consider origin of this technology in Bakerls patent (1929) titled "The use of an electric arc as a heat source to generate $3 \mathrm{D}$ objects by depositing molten metal in superimposed layers", in their researches wires of Ti-6Al-4V have been deposited layer by layer onto a base support, in single bead without weaving producing two straight walls 6.8 $\mathrm{mm}$ thickness, the first $925 \mathrm{~mm}$ long and $195 \mathrm{~mm}$ high and the second $975 \mathrm{~mm}$ long and 155 mm high.

For the manufactured walls using wire and arc additive manufacturing in the communication experimental results are presented related to: mechanical proprieties (the average yield strength (YS), ultimate tensile strength (UTS), and strain to failure from the baseline tests were $950 \pm 150 \mathrm{MPa}, 1033 \pm 100 \mathrm{MPa}$, and $11.7 \%$ ), fatigue properties (twentyone samples had a fatigue life well above three million cycles), fracture toughness testing, crack propagation at WAAM to wrought interface, the effect of cold rolling for each layer deposited using wire and arc additive manufacturing test pieces made in Ti-6Al-4V alloy and in the final part of scientific communication the researchers present complex parts manufactured for aeronautical industry like: landing gear rib, a frame demonstrator for BAE Systems and flap rib demonstrator for Fokker Aeronautics. 


\section{Objectives, methodology and procedure of this research}

At Iasi TCM department some experimental researches have been done for additive manufacturing using a self made device for fused object manufacturing of pieces for the car presented in formula Students, also same colleague uses a Z Corp 3D printing device to manufacture a small model of the car in powder and liquid binder. The pieces made using fused object manufacturing are presented in Figure 2, with the permission of our colleague.

In this research the main objective was to investigate if it is possible to weld layer upon layer of welded bead to form a vertical wall with good mechanical characteristics for further mechanical operation like milling.
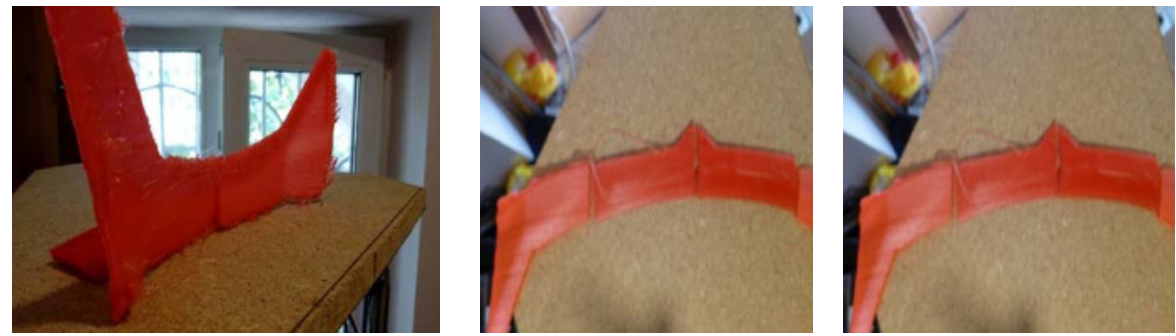

Fig. 2. Pieces manufacturing in plastic materials (PVC) made with the self made devices for Fused Object Manufacturing (FOM) with utilization in Formula Student car manufactured by the team lead by $\mathrm{PhD}$ Ciofu Ciprian (posted with his kind permission).

To achieve the objective the shielded metal arc welding process have been used with Technology Inverter 200 welding device, a $2.5 \mathrm{~mm}$ diameter shielded electrode type E 432 RR 22 (ISO 2560) or E 6013 (AWS A 5.1) with chemical composition of deposed material in \%: C 0.06-1; Mn 0.4-0.7; Si 0.2-0.6; S max. 0.04; $\mathrm{P}$ max. 0.04 and mechanical characteristic of deposed metal: Rp $\mathrm{p}_{0.2} 430-490 \mathrm{~N} / \mathrm{mm}^{2} ; \mathrm{Rm} 490-550 \mathrm{~N} / \mathrm{mm}^{2} ;$ A5\% min.24; KV-J 78 at $20{ }^{\circ} \mathrm{C}$, producer recommended welding current $60-80 \mathrm{~A}$, electrode manufactured with authorisation from Lloyd's Register of Shipping, American Bureau of Shipping, Bureau VERITAS.

The welded bead have been deposed on a plate with dimensions $100 \times 20 \times 8 \mathrm{~mm}$, polished to metallic shine with the speed of electrode around $20 \mathrm{~mm} / \mathrm{min}$, shot waving of electrode half diameter using $70 \mathrm{~A}$, each bead has been carefully cleaned for welding slag and quickly cooled at around $150{ }^{\circ} \mathrm{C}$, ten layer upon layer of welded bead have been deposed. The phases of experimental examination are presented in Figure 3 where could be seen: the support and fixing devices, the deposition of the first layer of welded bead and the colour of a layer of welded bead given by electric arc utilisation.

During experimental research preparation the definition of additive manufactured processes proposed by ASTM [6] stated that: "additive manufacturing (AM) a process of joining materials to make objects from 3D model data, usually layer upon layer, as opposed to subtractive manufacturing methodologies. Synonyms: additive fabrication, additive processes, additive techniques, additive layer manufacturing, layer manufacturing, and freeform fabrication' to make object from 3D model is very important part of this definition and this mean that the $3 \mathrm{D}$ model data controlled by a computer must be used as a design precursor and the further development of this experiment will be in this direction, but the objective of this research was to observe if important changes in internal structure of deposed welding bead will occur and this will be investigate by hardness and milling tests to understand if constructed material could be used for pieces manufacturing using machining technologies. 


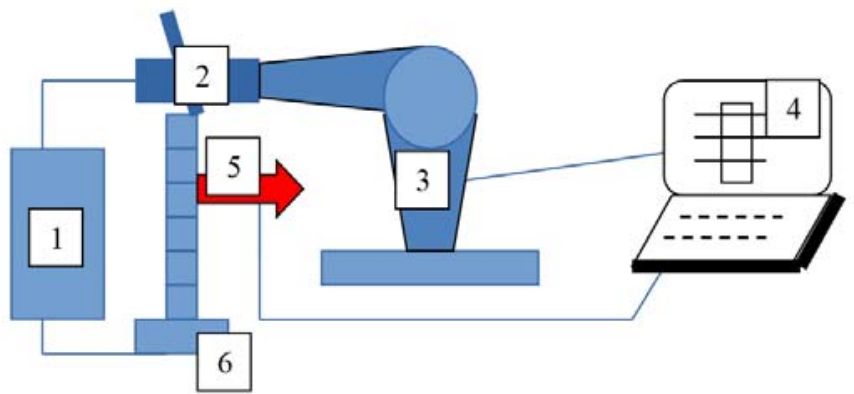

Fig. 3. Experimental stand for waam: 1- Welding machine; 2 - robotic catching device; 3 - robot IRR 120; 4 - process computer; 5 - temperature measurement device; 6 - test piece manufactured using waam technique; lines represent connectors.

\section{Results and Conclusions}

The phases of welding deposition layers are presented in Figure 4, could be seen the initial catching of metallic support in specific welding devices, the first layer deposition and attentive cleaning of surface and the colour of the other welding deposition layer because of the heat developed by electric arc used like heating source to melt the electrode
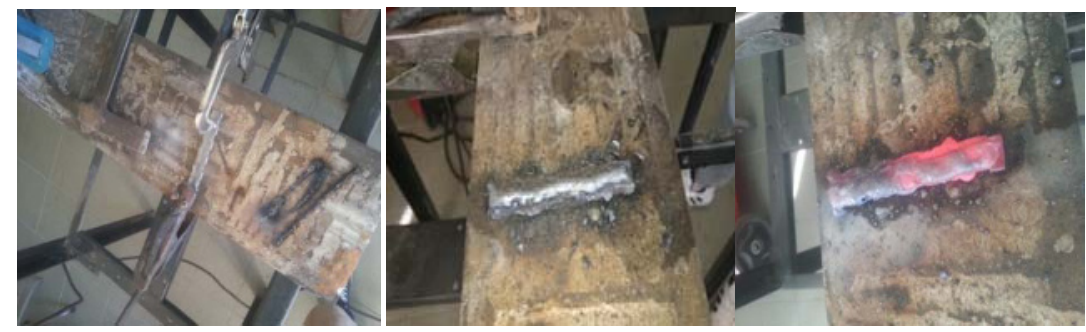

Fig. 4. Manufacturing phases for preliminary experiments using Shaped Deposition Metal (SDM) method our approach to wire and arc additive manufacturing.

After test piece manufacturing using wire and arc manufacturing (wam) in this case, the cutting of cross sections have been done for grinding surfaces to do micro-hardness tests, this operation give the first information that resulted pieces have not fragile internal structures. The resulted piece, the cross sections and micro-hardness measurement are shown in Fig. 5.

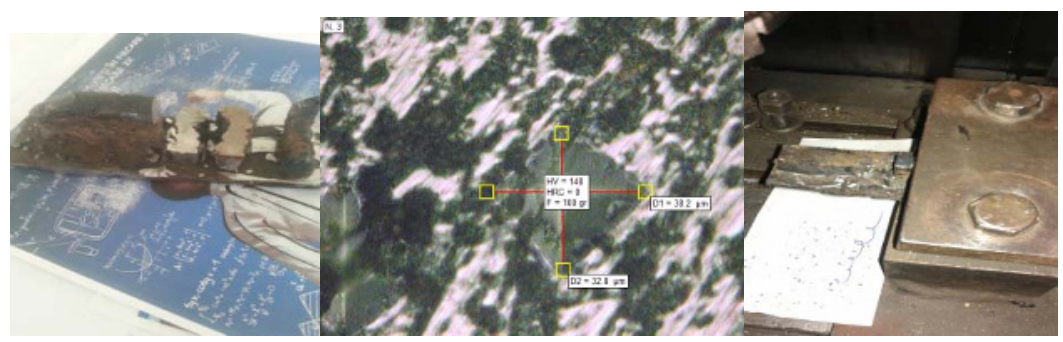

Fig. 5. The results of experimental wire and arc object manufacturing (WAOM). 
In this experimental research the prove that manufacturing objects using shielded wires with $2.5 \mathrm{~mm}$ diameter by adding one upon other layers consisting of welded bead it is shown and the method could be named wire and arc object manufacturing the processed piece was $80 \times 40 \times 8 \mathrm{~mm}$.

The measurements of micro-hardness in cross sections of deposited material from wire core of the shielded electrode did not change it values showing that internal structure is not composed by fragile part, in the experiments a high cooling speed of welded material has been used wishing to avoid repeated thermal cycles, using milling technology on test piece the process was smooth, with small cutting forces and the resulted cheeps has metallic colour with no burned zone showing that it is possible to use welded test pieces to manufacture precise mechanical elements.

\section{References}

1. Wohlers, T., Wohlers Report 2010, Wohlers Associates, Ft. Collins (2010)

2. Custom-fit.org, http://ec.europa.eu/research/headlines/news/article_09_02_16_en.html (2016)

3. Harris, I., Development and Implementation of Metals Additive Manufacturing Welding Institute presentation to the U.S. Department of Transportation (2011)

4. W.E. Frazier, J. Materials Engineering and Performance, 23 (6), 1917- 1928 (2014)

5. W.E. Frazier, Solid Free Form Fabrication Proceedings, Austin TX, 717-732 (2010)

6. E. Herderick, Proceedings of MS\&T, Additive Manufacturing of Metals, Columbus, $\mathrm{OH}$, (2011)

7. Adrian Addison, TITANIUM EUROPE 2015 (Birmingham, 11-13, 2015) 